\title{
CHOOSING THE RIGHT MEASURES TO IMPROVE COLLABORATION BETWEEN DESIGN AND SIMULATION DEPARTMENTS
}

\author{
S. Schweigert-Recksiek ${ }^{\otimes}$ and U. Lindemann \\ Technical University of Munich, Germany \\ $\square$ schweigert.recksiek@tum.de
}

\begin{abstract}
Increasing complexity of products and design processes leads to intensive collaboration of different stakeholders in technical product development. This causes a demand for suitable methods of collaboration across department interfaces, as between design and simulation. The paper investigates typical barriers of collaboration at this interface and measures to overcome them. Methods of complexity management form links based on literature and empirical data from online surveys and interview studies. The framework uses a set of structural metrics to analyse collaboration networks systematically.
\end{abstract}

Keywords: structural complexity, communication, process improvement, collaboration, design management

\section{Introduction}

With the diversification into different sub-disciplines like electronics, industrial design, informatics, as well as design and simulation, engineering design processes are complex systems (Kreimeyer, 2009), where communication plays an important role (Maier, 2007; Sosa et al., 2007), especially in inter-disciplinary design. Within this complex system, the focus of this paper is on the collaboration between design and simulation departments. This is and will be a major topic in design management as the number of simulations as well as their complexity and the generated data has increased dramatically within the last years and is about to continue that way (Reicheneder, 2015; Norris, 2017).

This paper combines empirical data on barriers between design and simulation departments with insights from communication science and structural metrics for network analysis. The presented approach is tailored to large organizations where design and simulation exist as two separate departments. However, many of the findings can be transferred to the collaboration of people from these two disciplines even if they are organised in a different way, e.g. when simulation is regarded as integrative part of design.

The overall goal is to provide recommendations for suitable improvement measures that take the specific situation of companies and their collaboration structure into account. This is important, as preliminary work has shown that standard measures like process standardization are the key to success for some companies while others regard it as not possible or necessary (SchweigertRecksiek et al., 2019). 


\section{State of the art}

\subsection{Inter-departmental collaboration in engineering design}

This work is grounded on the Conceptual Framework of Communication in Engineering Design by Maier (2007), in which she defines factors influencing communication in engineering design. A set of 120 recommendations for communication in engineering design are listed in Maier et al. (2011). They are the result of a systematic literature review and are finally grouped in the four categories 'information', 'individual', 'team', and 'organization'. They are applicable for any sort of communication in engineering design and are not limited to the focus of this paper - the collaboration between design and simulation departments. However, due to their generic nature, all of them are applicable for this specific area.

The understanding for the barriers this paper tries to overcome originates a combination of research from communication science by Eppler (2007) and insights from the field of human behaviour in design.

As in Maier (2007), communication in this research refers to the interaction between people and the transmission of information in a social and organizational context. It is part of collaboration, defined as the act of working together in a project or any other sort of goal-oriented activity. This is based on the "3C Collaboration Model" by Fuks et al. (2007), in which collaboration includes communication, coordination, and cooperation.

\subsection{Collaboration of design and simulation departments}

Previous work on the collaboration of these two departments has been conducted by Herfeld et al. (2006) and Deubzer et al. (2005), who analysed communication between design and simulation departments. Their results show that one of the main issues in CAD-CAE-integration is the unification of goals. As Herfeld puts it, now in the position as head of vehicle test department of an automotive OEM "A conflict of objectives is the central problem for efficient collaboration of design and simulation departments. While simulation experts try to design a product that meets all functions and requirements, design engineers are responsible for meeting time and cost targets." Beside this issue of goal setting, many tools help to simplify the collaboration. Schönwald et al. (2019), for example, showed in an empirical study that simulation data management tools are very beneficial and more widely used than for example test data management. Eriksson et al. (2014) as well as Petersson et al. (2013) emphasise, also based on an interview study, that CAD-integrated FEM systems are used systematically in design departments of many companies and that these simulations are performed efficiently.

\subsection{Structural analysis of collaboration networks}

As further described in the following sections, this research uses structural network analysis firstly to identify barriers in the collaboration of design and simulation departments and then to come up with suitable recommendations for improvement. Concerning structural analysis of engineering design collaboration networks and metrics for engineering design process, this research builds on the work of Kreimeyer and Lindemann (2011). Using the Goal-Question-Metric approach as described by Basili and Weiss (1984), Kreimeyer defines a set of metrics for engineering design processes. The resulting measurement system is used in this framework. A similar approach is described in Mathieson and Summers (2017). They describe a protocol that uses e-mail exchange and other data to build networks that can be analysed via network metrics. This can help to identify member roles and work schedules. Songhori and Nasiry (2019) built on the misalignment theory that compares organizational structures and product structures. This also includes analyses of the decision making structure that can be applied to the collaboration of design and simulation departments as well.

\section{Methodology}

\subsection{Research gap and research questions}

As previous research on the integration of simulations like FEM and CFD in the product development process has focused mainly on technical aspects such as tools and data, there is a need to further 
investigate the dimensions of people and process (Motte et al., 2014). Especially, a systematic way to identify suitable improvement measures building on an empirical foundation is missing.

Therefore, the following research questions have to be asked:

- RQ1: What are typical barriers in the collaboration of design and simulation departments?

- RQ2: What are appropriate measures to enhance communication and collaboration between design and simulation departments?

- RQ3: How can barriers of collaboration and improvement measures to overcome these barriers be matched taking into account the specific boundary conditions and collaboration structure of different companies?

\subsection{Research design}

This framework was built using the design research methodology by Blessing and Chakrabarti (2009). As they propose for the visualisation and structuring of research projects, the following reference model was built (Figure 1).

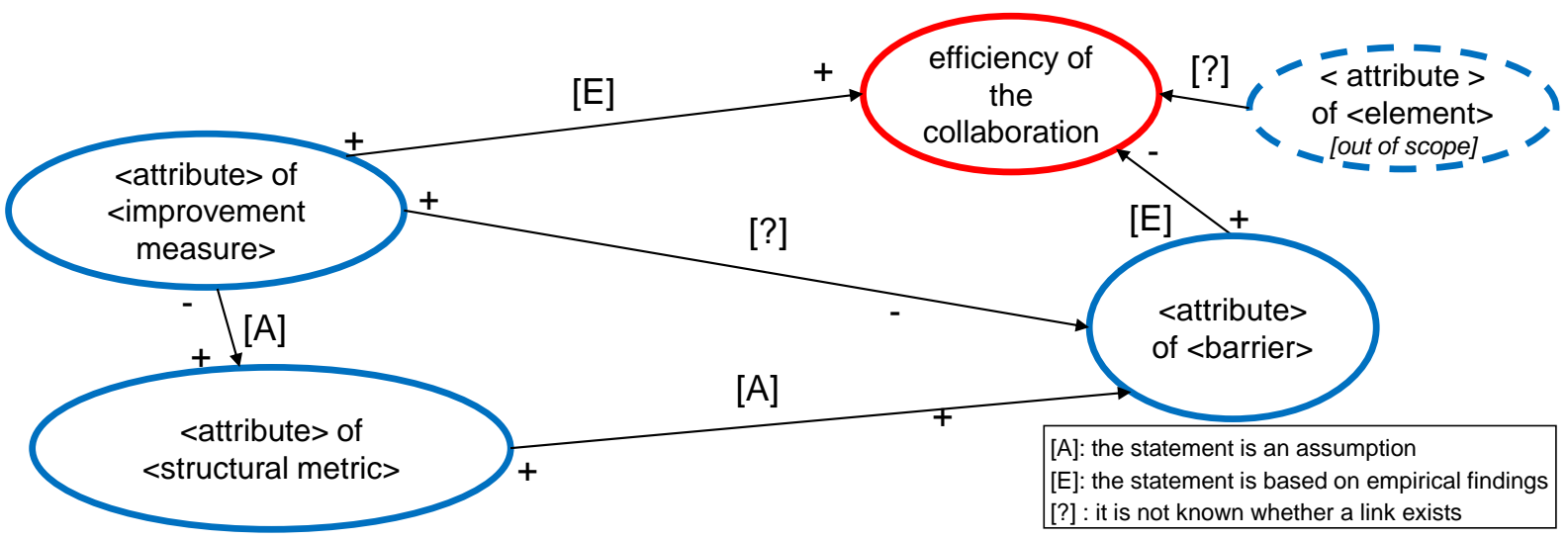

Figure 1. Reference model according to Blessing and Chakrabarti (2009)

It shows how empirical data is used to investigate which barriers hinder efficient collaboration and which improvement measures support it. Structural metrics are used to connect barriers and recommendations for improvement measures or to identify barriers in collaboration networks. The findings are generic and can be applied to any company with design and simulation departments.

\subsection{Preliminary work}

Some preliminary work has been published on parts of the approach this paper presents as a whole. Schweigert et al. (2017a) initially showed an earlier version of the framework. Knippenberg et al. (2018) presents the structural metrics and their implementation in a graph analysis tool in detail. Schweigert-Recksiek and Lindemann (2018) elaborates on the barriers between design and simulation departments while Schweigert-Recksiek et al. (2019) builds the connection between barriers and recommendations based on a multivariate analysis of survey data coming from Schweigert et al. (2017b). All these parts are integrated in the framework of this paper, supplemented by the description of the research methodology and questions, the table of recommendations as well as an industrial case study.

\section{Results}

\subsection{The framework}

Figure 2 shows the overall approach of this paper (extended from Schweigert et al., 2017a). It consists of four generic phases: situation description, characterization, measure selection, and implementation. The upper row shows the inputs for each phase, while the outputs are depicted below the phases. 


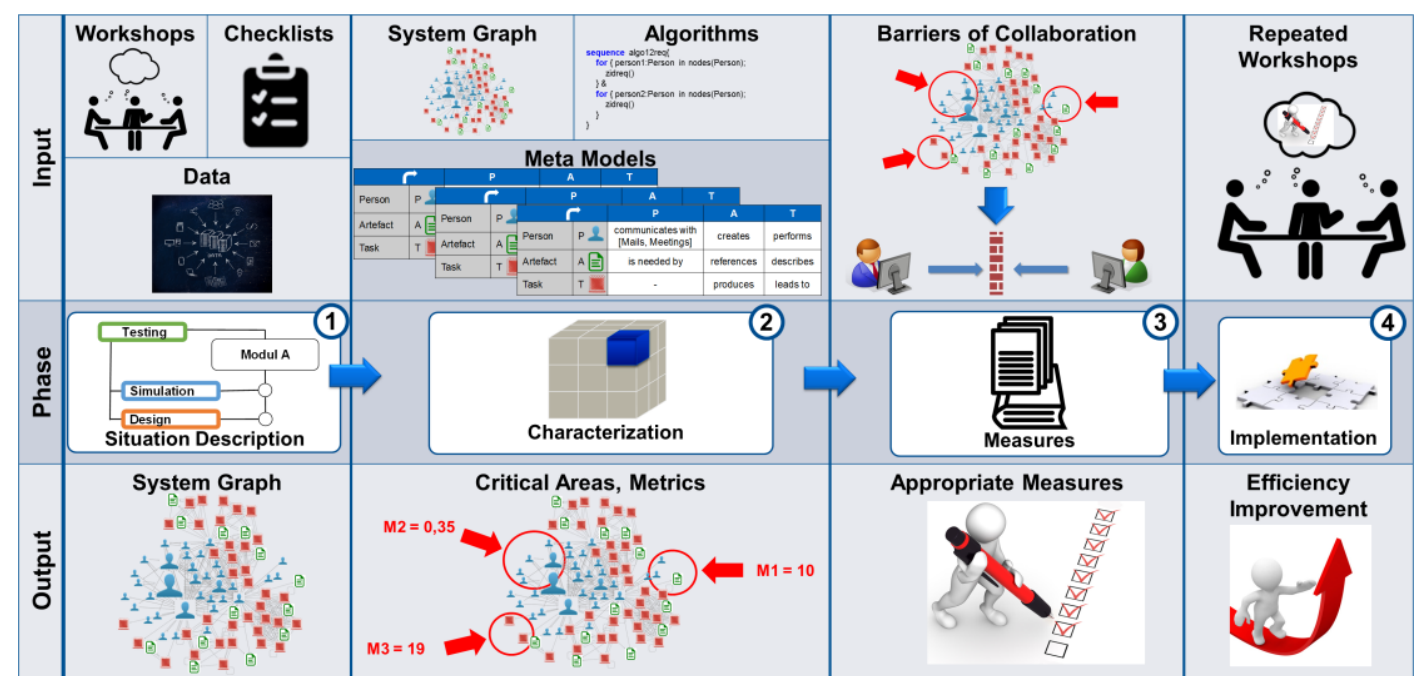

Figure 2. Approach for the improvement of collaboration between design and simulation departments (extended form Schweigert et al., 2017a)

Workshops, checklists, and data analysis (e.g. email correspondence, meeting calendars) are used to form system graphs of collaboration in phase 1. These graphs are analysed in phase $\mathbf{2}$ based on the metamodel in Figure 3 to come up with structural metrics that can identify possible barriers on the one hand and help implement improvement measures downstream in the process. By a comparison with typical barriers of design and simulation departments in phase 3, the specific barriers of a given company are identified before they are mapped to fitting measures to overcome them. This forms the input of repeated workshops in phase 4, where the final measures for implementation are selected in order to improve the overall efficiency of the collaboration between design and simulation departments.

\begin{tabular}{|l|c|c|c|c|}
\hline \multicolumn{2}{|c|}{} & P & A & T \\
\hline Person & $\mathrm{P} \Omega$ & $\begin{array}{c}\text { communicates with } \\
\text { [Mails, Meetings] }\end{array}$ & creates & performs \\
\hline Artefact & $\mathrm{A}$ & is needed by & references & describes \\
\hline Task & $\mathrm{T}$ & - & produces & leads to \\
\hline
\end{tabular}

Figure 3. Metamodel for the collaboration of design and simulation departments

For the approach shown in Figure 2, three scenarios were elaborated (cf. Table 1):

1. A given company wants to improve collaboration without specific preparation.

2. A given company knows, where their specific barriers are and wants to overcome them.

3. A given company has already decided, which measures to implement, but does not know how and where exactly.

Table 1. Scenarios how to use the approach

\begin{tabular}{|l|l|l|}
\hline $\begin{array}{l}\text { Preparation } \\
\text { of the company }\end{array}$ & \multicolumn{2}{|c|}{ Scope } \\
\hline \hline \multirow{2}{*}{ No preparation } & $\begin{array}{l}\text { Whole Process: Phases 1-4 } \\
\text { Metric-based identification of barriers and } \\
\text { recommendations }\end{array}$ & $\begin{array}{l}\text { Short Process: Phases 1,3,4 } \\
\text { Checklist-based identification of } \\
\text { barriers } \\
\text { Matrix-based selection of measures }\end{array}$ \\
\hline $\begin{array}{l}\text { Identified } \\
\text { Barriers }\end{array}$ & Metric-based identification of recommendations & Matrix-based selection of measures \\
\hline $\begin{array}{l}\text { Selected } \\
\text { Measures }\end{array}$ & Metric-based implementation & $\begin{array}{l}\text { Workshop-based implementation } \\
\text { support }\end{array}$ \\
\hline
\end{tabular}


For Scenario 1, the whole approach (phases 1 to 4) is gone through. After gathering data (phase 1) and characterizing the situation (phase 2) via system graphs (a) or only based on workshops (b), recommendations for improvement are made (phase 3). These recommendations lead to measures that are implemented (phase 4) based on metrics (a) or only based on additional workshops (b).

For Scenario 2, where barriers have already been identified, either additional data is acquired and analysed (phases 1 and 2; a) or recommendations for improvement are derived directly in workshops (b; phase 3). These measures are either implemented based on metrics (step 4; a) or only based on workshops (b).

For Scenario 3, where measures have already been chosen, either additional data is acquired and analysed (back to phases 1 and 2; a) to support the implementation (phase 4; a) or merely the implementation of measures is supported by workshops and tools (phase $4 ; b$ ).

\subsection{The ingredients}

\subsubsection{Barriers of interdepartmental collaboration}

The barriers in the collaboration between design and simulation departments that are used in this paper are grounded on the findings of an online survey described in Schweigert et al. (2017b) and a following interview study (Schweigert-Recksiek and Lindemann, 2018). The list of 20 barriers is based on 31 communication barriers as described in Eppler (2007), who reviewed findings from social and engineering sciences, and classified knowledge communication barriers into three groups: barriers that affect mainly managers, those relevant for experts, and those important for both roles. These 31 barriers were used in the composure of the interview guide for the study described in Schweigert-Recksiek and Lindemann (2018). Figure 4 lists the resulting typical barriers between design and simulation departments.

\begin{tabular}{|c|c|c|c|c|c|}
\hline \multirow{8}{*}{$\begin{array}{l}\frac{1}{\circ} \\
\frac{0}{8} \\
\stackrel{0}{0}\end{array}$} & B06 & Generation gap & \multirow{10}{*}{$\begin{array}{l}\text { g. } \\
\text { \& } \\
\text { 온 } \\
\text { ․ }\end{array}$} & \multirow{2}{*}{ B01 } & \multirow{2}{*}{ Difficulties in Concurrent Engineering } \\
\hline & B07 & Handling different human characters & & & \\
\hline & B09 & $\begin{array}{l}\text { Interdepartmental communication and feedback } \\
\text { culture }\end{array}$ & & B03 & $\begin{array}{l}\text { Challenging coordination of design and simulation } \\
\text { processes }\end{array}$ \\
\hline & $\mathrm{B} 10$ & $\begin{array}{l}\text { Lacking acceptance and inadequate understanding } \\
\text { of the capabilities of simulation experts }\end{array}$ & & B04 & $\begin{array}{l}\text { Inefficient frontloading and dependency of } \\
\text { simulation on design and test departments }\end{array}$ \\
\hline & B12 & Mistrust in simulation results & & B11 & Missing structures of collaboration (e.g. trigger \\
\hline & B13 & No close coupling between departments (e.g. global & & & points) \\
\hline & & distribution and central simulation department) & & B14 & No customer focus \\
\hline & B15 & $\begin{array}{l}\text { Physical distance that prevents face-to-face } \\
\text { communication }\end{array}$ & & B16 & $\begin{array}{l}\text { Lack of transparency in the prioritization of } \\
\text { simulation orders }\end{array}$ \\
\hline \multirow{3}{*}{ อั } & B05 & $\begin{array}{l}\text { Conflict between explanation of complex issues vs. } \\
\text { high documentation effort }\end{array}$ & & B17 & $\begin{array}{l}\text { Redundant time-consuming iterations (e.g. due to } \\
\text { outdated geometries) }\end{array}$ \\
\hline & B08 & $\begin{array}{l}\text { Lacking information sharing towards the simulation } \\
\text { department }\end{array}$ & & $\mathrm{B} 18$ & Standardization in the presence of diverse projects \\
\hline & B19 & Unstructured information sharing & \multirow{2}{*}{$\begin{array}{l}\text { 흠 } \\
\text { 응 } \\
\text { 은 }\end{array}$} & \multirow[b]{2}{*}{ B02 } & \multirow{2}{*}{$\begin{array}{l}\text { Conflict of objectives between design, simulation, } \\
\text { and test }\end{array}$} \\
\hline$\frac{\infty}{\circ}$ & B20 & Inefficient usage of CAD-integrated FEM systems & & & \\
\hline
\end{tabular}

Figure 4. Set of barriers between design and simulation departments (adapted from Schweigert-Recksiek and Lindemann, 2018)

\subsubsection{Recommendations for improvement measures}

The basis of the results in this paper is an understanding of communication in engineering teams and especially between design and simulation departments. Table 2 lists the recommendations that are a result of a systematic literature review. Hundreds of papers mainly from engineering design journals were analysed and a final set of 131 sources was used to formulate the recommendations under the influence of Maier et al. (2011). Table 2 also shows the transfer of these generic recommendations in column one to the topic of collaboration between design and simulation departments in column two based on examples from the expert interviews. The term "expert" is used according to the defintion of Liebold and Trinczek (2009), as a person with detailed and specialized knowledge in a certain, clearly defined domain - in this case the collaboration of design and simulation departments. Concrete methods and tools, on which more material is available for the implementation workshops of phase four, are marked in bold. 
Table 2. Recommendations and transfer to collaboration between design and simulation departments (concrete methods and tools in bold; part 1)

\begin{tabular}{|c|c|c|}
\hline \# & Generic recommendation & Transfer to design and simulation \\
\hline 1 & $\begin{array}{l}\text { Effort and good information } \\
\text { transmission in the initial phases }\end{array}$ & $\begin{array}{l}\text { Use hand-drawn sketches in kick-off meetings that include } \\
\text { members of both design and simulation department }\end{array}$ \\
\hline 2 & $\begin{array}{l}\text { Scheduling and identification of } \\
\text { priorities and needs }\end{array}$ & $\begin{array}{l}\text { Introduce trigger points for communication in the overall design } \\
\text { process (e.g. via decision meetings using the RACI Method) }\end{array}$ \\
\hline 3 & $\begin{array}{l}\text { Appropriate information sharing among } \\
\text { departments during product } \\
\text { development }\end{array}$ & $\begin{array}{l}\text { Preparation and pre-configuration of the CAD-integrated FEM } \\
\text { systems }\end{array}$ \\
\hline 4 & Information sharing tools and networks & Use shared PDM and SDM systems \\
\hline 5 & $\begin{array}{l}\text { Understanding of the entire project at } \\
\text { all levels and common terminology }\end{array}$ & $\begin{array}{l}\text { Encourage communication between departments via simulation } \\
\text { templates and simulation reports }\end{array}$ \\
\hline 6 & $\begin{array}{l}\text { Interaction and sharing questions, } \\
\text { ideas, and values }\end{array}$ & Shared offices between design and simulation department heads \\
\hline 7 & $\begin{array}{l}\text { Approach of conflicts pro-actively and } \\
\text { close communication to resolve them }\end{array}$ & Push for regular personal meetings (cf. Scrums) \\
\hline 8 & $\begin{array}{l}\text { Feedback, reviews, and evaluations at } \\
\text { all levels }\end{array}$ & $\begin{array}{l}\text { Implement a change process with automatic trigger points for } \\
\text { reviews }\end{array}$ \\
\hline 9 & Team motivation and rewards & $\begin{array}{l}\text { Conduct teambuilding measures, especially for internationally } \\
\text { distributed design and simulation teams }\end{array}$ \\
\hline 10 & $\begin{array}{l}\text { Examination and evaluation of the } \\
\text { factors involved in each decision }\end{array}$ & Employ decision makers that respect simulation results \\
\hline 11 & $\begin{array}{l}\text { Empowerment of the skills of } \\
\text { employees through education and } \\
\text { training }\end{array}$ & $\begin{array}{l}\text { Training and mentoring of design engineers by simulation } \\
\text { experts when using CAD-integrated FEM-systems }\end{array}$ \\
\hline 12 & $\begin{array}{l}\text { Experienced designers and experience } \\
\text { of previous successful projects }\end{array}$ & $\begin{array}{l}\text { Use lessons learned meetings after projects as well as best } \\
\text { practice databases }\end{array}$ \\
\hline 13 & $\begin{array}{l}\text { Definition of clear and specific } \\
\text { objectives }\end{array}$ & $\begin{array}{l}\text { Combine the functional goals of the simulation department and } \\
\text { the cost-driven and size-driven goals of the design departments } \\
\text { in kick-off workshops }\end{array}$ \\
\hline 14 & $\begin{array}{l}\text { Choice of right people for each job and } \\
\text { trust in their responsibilities }\end{array}$ & $\begin{array}{l}\text { Provide simulation experts in central simulation departments } \\
\text { with responsibilities instead of merely using them as service } \\
\text { providers for the design departments }\end{array}$ \\
\hline 15 & $\begin{array}{l}\text { Clear definition of jobs and } \\
\text { expectations }\end{array}$ & $\begin{array}{l}\text { Define clear division of tasks between design and simulation } \\
\text { departments in initial phases of the project (e.g. via process } \\
\text { standardization/tailoring) }\end{array}$ \\
\hline 16 & $\begin{array}{l}\text { Reinforcement of organizational values } \\
\text { and appropriate management style }\end{array}$ & Actively advertise the capabilities of simulation departments \\
\hline
\end{tabular}

\subsection{The connection between barriers and recommendations}

The connections between barriers and recommendations were drawn mainly from the interview study described in Schweigert-Recksiek and Lindemann (2018) as well as the survey data analysed in Schweigert-Recksiek et al. (2019). Also, all of the interviewed experts not only mentioned barriers in the collaboration of the departments, but also named improvement measures that are either already implemented in their companies or are suitable to overcome the barriers in their opinion. Furthermore, every barrier from Figure 1 is connected to an underlying reason for communication barriers from Eppler (2007). Using this foundation and understanding built up by the literature review and the empirical studies, connections were drawn between the recommendations in Tables 2 and 3 and the barriers in Figure 1. The resulting connections were double-checked by the factors of communication from Maier et al., 2011. The result is a connection matrix that links the identified 20 barriers with the 16 recommendations (Figure 5). As the barriers 
6, 7 and 14 are rather generic, no specific connection could be derived from the survey data so that they are only linked to recommendations based on the expert interviews. For barriers 16, 18, and 19, no matching link was found in both the expert interviews as well as the survey data. Therefore, only survey data was used to link them to appropriate recommendations.

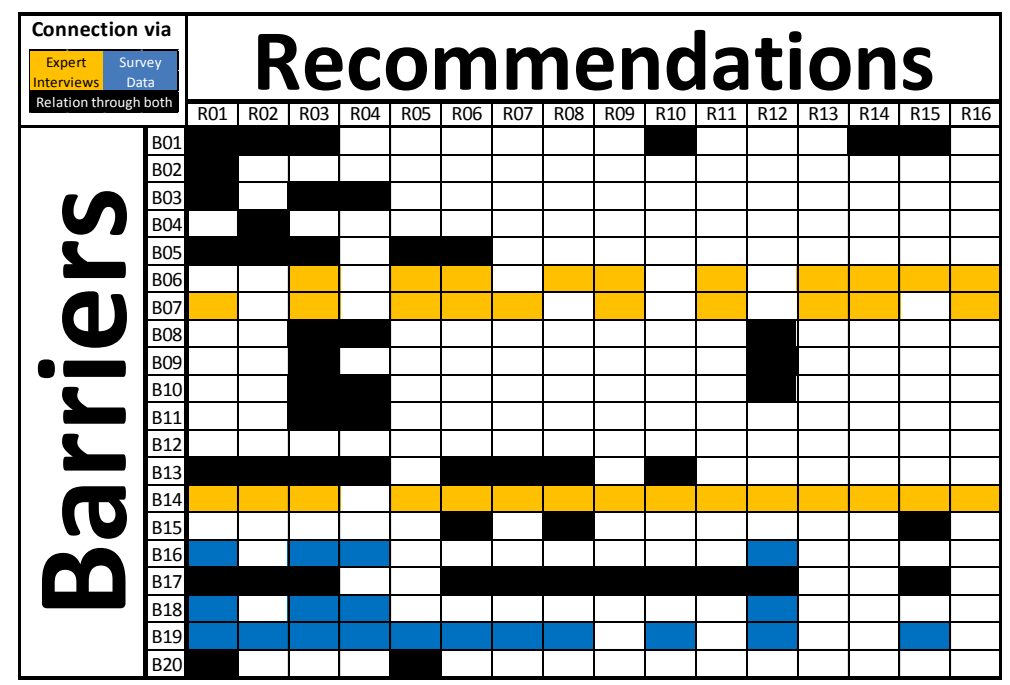

Figure 5. Connection matrix linking barriers and recommendations

Table 3. Adapted set of metrics for design and simulation departments (part 1)

\begin{tabular}{|c|c|c|c|}
\hline$\#$ & $\begin{array}{l}\text { Metrics of } \\
\text { Kreimeyer (2009) }\end{array}$ & Adapted Metrics & Barriers \\
\hline \multirow{5}{*}{8} & \multirow{5}{*}{$\begin{array}{l}\text { Number of } \\
\text { unconnected nodes }\end{array}$} & $\begin{array}{l}\text { M } 7.1 \text { Number of unconnected people (especially if they are } \\
\text { indirectly connected via tasks or artefacts) }\end{array}$ & B $8,10,17$ \\
\hline & & $\begin{array}{l}\text { M } 7.2 \text { Number of unconnected nodes across departments } \\
\text { (simulation engineers who do not participate in design } \\
\text { tasks/meetings) }\end{array}$ & B 9, 12 \\
\hline & & $\begin{array}{l}\text { M 7.3 Number of designers who do not use CAD-integrated } \\
\text { systems }\end{array}$ & B 20 \\
\hline & & M 7.4 Number of unconnected people to tasks & B $8,10,17$ \\
\hline & & $\begin{array}{l}\text { M 7.5 Number of unconnected Artefacts to people (Person does } \\
\text { not have access to task-relevant artefact/information) }\end{array}$ & $\begin{array}{l}\text { B 4, 8, 17, } \\
19\end{array}$ \\
\hline 15 & $\begin{array}{l}\text { Number of } \\
\text { feedbacks }\end{array}$ & $\begin{array}{l}\text { M } 15.1 \text { Number of feedbacks between design and simulation } \\
\text { engineers }\end{array}$ & B 8, 16 \\
\hline
\end{tabular}

\subsection{Systematic network analysis with structural metrics}

Based on the work on structural metric for engineering design processes by Kreimeyer (2009), a set of 16 metrics for the collaboration of design and simulation departments was defined (all of them listed in Knippenberg et al. (2018)). Its purpose is to identify possible barriers of collaboration or support the implementation of a certain improvement measure. Using the Goal-Question-Metric approach by Basili et al. (1994), it was ensured that there is at least one metric each that indicates the existence of the 20 barriers or the effect of the 16 recommendations as stated in the reference model in Figure 1.

Figure 6 shows an example of the connection of barriers, recommendations and metrics. 


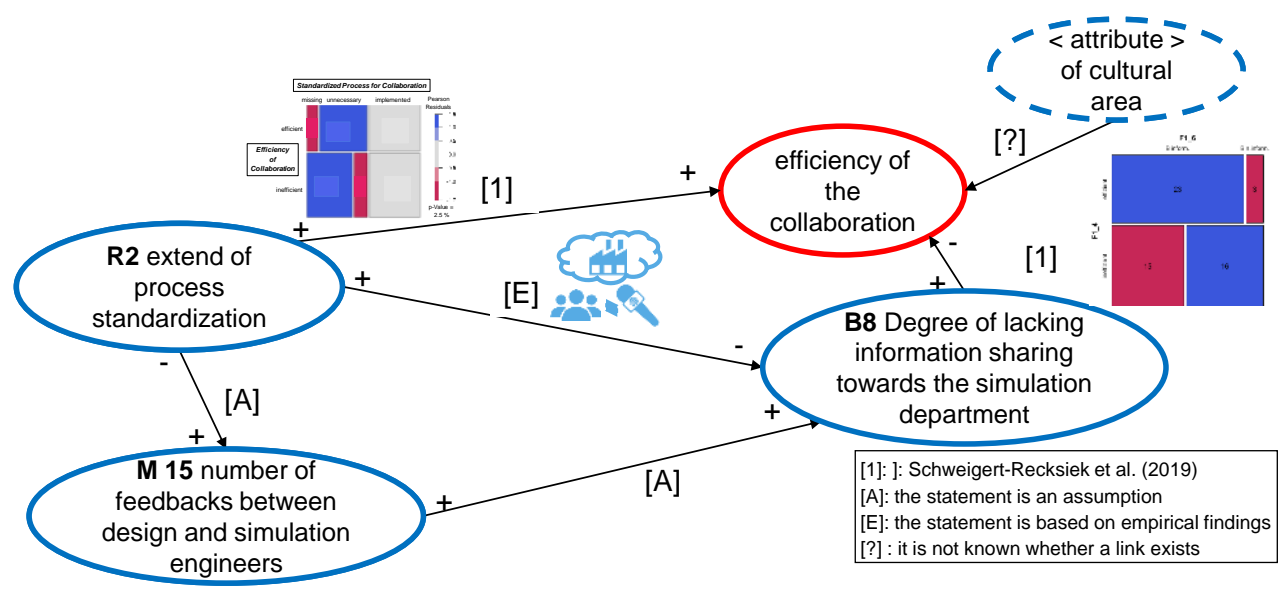

Figure 6. Reference model using the connection between process standardization and lacking information sharing towards the simulation department

As shown in the interview study ([E] in Figure 6) described in Schweigert-Recksiek and Lindemann (2018), there is connection between recommendation R2 (Introduce trigger points for communication in the overall design process (e.g. via decision meetings using the RACI Method)) and barrier B8 (Lacking information sharing towards the simulation department). Both of them can be directly linked to the efficiency of collaboration with the survey data analysed in Schweigert-Recksiek et al. (2019). Metric 15.1 (Number of feedbacks between design and simulation engineers) is assumed to be a good indicator for the extend of barrier B8 as well as a measure on how successful recommendation R2 was implemented. Table 4 shows two examples of the metrics listed in Knippenberg et al. (2018) and how they are used in this framework. Metrics of Kreimeyer (2009) are first adapted to the context of the collaboration of design and simulation departments, before the last column links them to one or several of the barriers. Due to the page limit, not all 16 metrics are presented here, but the explanatory example of M8 (Number of unconnected nodes) and M15 (Number of feedbacks).

Table 4. Participants of the case study workshops

\begin{tabular}{|c||c|}
\hline$\#$ & Position \\
\hline \hline $\mathbf{1}$ & Head of Processes, Methods, and Tools \\
\hline $\mathbf{2}$ & Function Development Engineer \\
\hline $\mathbf{3}$ & Diagnosis Analyst \\
\hline $\mathbf{4}$ & Series Production Engineer \\
\hline $\mathbf{5}$ & Design Engineer \\
\hline $\mathbf{6}$ & Head of Function Development \\
\hline
\end{tabular}

The metrics stated above can be calculated semi-automatically from system graphs. This gives the opportunity of identifying barriers in a given network, systematically or support the implementation of improvement measures based on the current collaboration structure.

\section{Application in a case study}

As shown in Table 1, the framework can be used in different scenarios. For a first case study with an industry partner from a heating systems company, a workshop-based approach without specific data preparation was used. Current development processes were analysed and target processes were formulated as part of a case study to implement a digital twin (cf. Schweigert-Recksiek et al., 2020). In order to better integrate the simulation department in the product development process, six workshops with participants from different departments were conducted (cf. Table 4).

19 out of the 20 barriers (cf. Figure 1) were confirmed by at least one expert, most of them by more (average confirmation of 3.6 out of 6). There was no confirmation for barrier B14 (No customer focus). Three of the barriers were confirmed by all experts, one of them being B4 (Inefficient frontloading and 
dependency of simulation on design and test departments). As this barrier was rated as the most hindering one in the current collaboration by the participants, an improvement measure was search for that can overcome it. According to the connection matrix in Figure 5 R02 (Scheduling and identification of priorities and needs - decision meetings using the. RACI Method) is suitable here. RACI refers to Responsible, Accountable, Consulted, Informed. Figure 7 shows a part of the new target process for a tolerance analysis. After the simulation department analyses the tolerances with FEM simulations and created an analysis report (red boxes), a simulation engineer is integrated in a consulting role in the decision meeting about the correctness of the draft, the design department is accountable for.

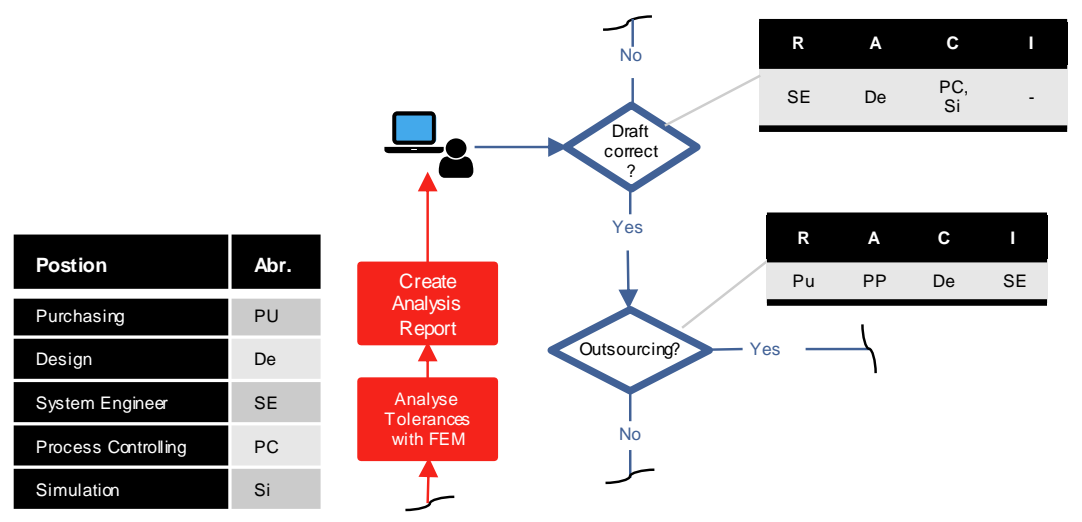

Figure 7. Part of the target process for a tolerance analysis

This approach was applied on a total of six new target processes with the result of a far more intensive integration of simulation engineers in the decision process. As from now on simulation experts will be part of the decision meetings instead of just providing analysis reports for them, their integration into the overall information flow is enhanced, which helps to make frontloading of simulations more efficient in following projects, as they already know which information is important for the decision meetings and how it has to be presented.

\section{Discussion and outlook}

The results of this paper enable the analysis of complex networks of the collaboration between design and simulation departments. Despite the effort spent on building a reliable foundation, limitations remain. Built on the results of both an empirical as well as a literature-based study, the connections between barriers and recommendation seem reliable. However, it is thus far only partly grounded on extensive and statistically relevant data that would include representative data from multiple companies in various regions and industries. Still it was possible to answer all research questions: A set of typical barriers in (RQ1) as well as improvement measures (RQ2) for the collaboration of design and simulation departments are presented. They are matched, taking into account the boundary conditions and collaboration structure of a given company (RQ3). First evaluations with companies not part of the initial interview study have affirmative results. Future research will focus on the implementation of the presented concepts, mostly in graph-based complexity management tools. The authors have started a research project with a Swiss automotive supplier to prove the applicability in a large and complex organisation. The validity of both, the connections between barriers and recommendations as well as the applicability of the recommendations to enhance collaboration will be tested here. Therefore, a tool for the semi-automatic analysis of networks will be provided and applied in the industry case studies.

\section{Acknowledgement}

The authors thank Elena Muro for her work in building this framework as well as Carsten Engel and Karsten Spreitzer of Viessmann Werke Allendorf GmbH for their support in the industrial application of it.

\section{References}

Basili, V.R. and Weiss, D.M. (1984), “A Methodology for Collecting Valid Software Engineering Data”, IEEE Transactions on Software Engineering, Vol 1. https://doi.org/10.1007/3-540-27662-9_7 
Blessing, L.T. and Chakrabarti, A. (2009), "DRM: A design research methodology", Springer London. https://doi.org/10.1007/978-1-84882-587-1_2

Deubzer, F. et al. (2005), "A structured holistic approach for the integration of CAD and CAE environments", ProSTEP iViP Science Days 2005 - Cross Domain Engineering. Darmstadt, ProSTEP iViP Association.

Eppler, M. (2007), "Knowledge communication problems between experts and decision makers: An overview and classification", The Electronic Journal of Knowledge Management, Vol. 5 No. 3, pp. 291-300.

Eriksson, M. et al. (2014), "Interaction between Computer-based Design Analysis Activities and the Engineering Design Process - An Industrial Survey”, International Design Conference. Dubrovnik: DESIGN2014.

Fuks, H. et al. (2007). The 3C collaboration model. https://doi.org/10.4018/978-1-59904-000-4.ch097.

Herfeld, U. et al. (2006), Verknüpfung von Komponenten und Funktionen zur Integration von Konstruktion und Simulation in der Karosserieentwicklung. VDI BERICHTE, 1967 (1), p. 259.

Knippenberg, S.C. et al. (2018), “Analyzing complex socio-technical systems in technical product development using structural metrics”, In International Dependency and Structure Modeling (DSM) Conference, p. 203.

Kreimeyer, M. and Lindemann, U. (2011), "Complexity metrics in engineering design: managing the structure of design processes", Springer Science \& Business Media.

Kreimeyer, M.F. (2009), "A Structural Measurement System for Engineering Design Processes (PhD Thesis)", Technical University of Munich. https://doi.org/10.1007/978-3-642-20963-5_5

Liebold, R. and Trinczek, R. (2009), "Experteninterview", In: Handbuch Methoden der Organisationsforschung: Springer, pp. 32-56. https://doi.org/10.1007/978-3-531-91570-8_3

Maier, A.M. (2007), "A Grid-Based asssessment method of communication in Engineering design (PhD Thesis)", University of Cambridge.

Maier, A.M. et al. (2011), "Improving communication in design: recommendations from the literature", In DS 687: Proceedings of the 18th International Conference on Engineering Design (ICED 11), Impacting Society through Engineering Design, Vol. 7: Human Behaviour in Design, 15-19 August 2011, Lyngby/ Copenhagen, Denmark.

Mathieson, J. and Summers, J.D. (2017), “A protocol for modeling and tracking engineering design process through structural complexity metrics applied against communication networks", Concurrent Engineering, Vol. 25 No. 2, pp. 108-122. https://doi.org/10.1177/1063293x16666936

Motte, D. et al. (2014), "Integration of the computer-based design analysis activity in the engineering design process", Proceedings of the 10th International Symposium on Tools and Methods of Competitive Engineering, Delft University of Technology, pp. 1181-1194.

Norris, M. (2017), "How to succeed @ SPDM", International SPDM Conference 2017. NAFEMS. Stockholm.

Petersson, H., Eriksson, M. and Bjärnemo, R. (2013), "Integration of Computer Aided Design Analysis Into the Engineering Design Process for Use by Engineering Designers", Proceedings of the International Mechanical Engineering Congress \& Esposition. San Diego: IMECE2013. https://doi.org/10.1115/imece2013-62130

Reicheneder, J. (2015), “15 Years SPDM@BMW”, NAFEMS Europeans SPDM Conference. Munich: NAFEMS.

Schönwald, J.R. et al. (2019, July), "Improvement of Collaboration between Testing and Simulation Departments on the Example of a Motorcycle Manufacturer", In Proceedings of the Design Society: International Conference on Engineering Design, Cambridge University Press, Vol. 1, No. 1, pp. 149-158. https://doi.org/ 10.1017/dsi.2019.18

Schweigert, S. et al. (2017a), "Combination of Matrix-based and Graph-based Modeling for Product and Organizational Structures", Proceedings of the 19th International DSM Conference Espoo (Finland), September 2017, pp. 11-13.

Schweigert, S., Xia, M. and Lindemann, U. (2017b), "An empirical survey on efficiency improvement for the collaboration between design and simulation departments", The 21st International Conference on Engineering Design ICED17, Vancouver, Canaca, The Design Society, pp. 337-346.

Schweigert-Recksiek, S. and Lindemann, U. (2018), "Improvement Opportunities for the Collaboration of Design and Simulation Departments - An Interview Study", The international Design Conference on Engineering Design, Zagreb, The Design Society, pp. 905-916. https://doi.org/10.21278/idc.2018.0393

Schweigert-Recksiek, S., Koch, C. and Lindemann, U. (2019), "Matrix-Based Multivariate Analysis of Survey Data on Potentials for the Collaboration of Design and Simulation", Proceedings of the 21st International DSM Conference (DSM 2019), 23-25 September 2019, Monterey, California. https://doi.org/10.35199/dsm2019.1

Schweigert-Recksiek, S. et al. (2020), "Conception of a Digital Twin in Mechanical Engineering: A Case Study in Technical Product Development”, DESIGN2020 (accepted).

Songhori, M.J. and Nasiry, J. (2019), “Organizational Structure, Subsystem Interaction Pattern, and Misalignments in Complex NPD Projects", Production and Operations Management. https://doi.org/10.2139/ssrn.3448496

Sosa, M.E., Eppinger, S.D. and Rowles, C.M. (2007), "Are your engineers talking to one another when they should?", In: Harvard Business Review, Vol. 85 No. 11, p. 133. 